\title{
Ecological risk assessment of chemical contaminants in stormwater sediments
}

\author{
Aleksandra Sałata ${ }^{1, *}$, Lukasz Bąk ${ }^{1}$, and Jarosław Górski ${ }^{1}$ \\ ${ }^{1}$ Kielce University of Technology, Faculty of Environmental, Geomatics and Energy Engineering Al. Tysiąclecia Państwa Polskiego 7, \\ 25-314 Kielce, Poland
}

\begin{abstract}
Contaminants bound to suspended solids transported by stormwater pose quantity and quality problems to the water ecosystem. Therefore, it is necessary to carry out an ecological risk assessment. Currently, Polish legal regulations do not require that stormwater sediments should be tested for hazardous substances prior to their removal. Ecological evaluation was performed for polycyclic aromatic hydrocarbons (PAHs) and heavy metals in the sediments from three selected stormwater sedimentation tanks located in urban catchment areas of Kielce city. The purpose this study was to analyze sediments for chemical contaminants and to demonstrate the relationship between contaminant levels and physical attributes of the catchment, including land use, drainage area, age of catchment and impervious surface in the watershed. Levels of PAHs and heavy metals $(\mathrm{Cd}, \mathrm{Cr}, \mathrm{Ni}, \mathrm{Pb}$ and $\mathrm{Zn})$ in stormwater sediments were then compared with Polish regulations and ecological screening values to determine their potential risk to environment were established. The results of the current study suggest that stormwater sediments are moderately contaminated with PAHs and heavy metals according to domestic regulations. They are, however, highly contaminated according to ecological benchmarks, which are exceeded several times.
\end{abstract}

\section{Introduction}

Migration of contaminants from rainwater occurs in several stages: atmospheric precipitation, runoff in the catchment area and rainwater flow through the stormwater drainage system. Rainwater from urban areas has varied composition and can be a source of many dangerous chemical compounds [1,2,3]. Most pollutants are accumulated on particulates of various sizes. Sediments are formed as a result of sedimentation of mineral and organic suspensions derived from the erosion processes. Sediments are also produced from components precipitating from water. In treatment facilities, more sediment is commonly found close to the inlet than the outlet, because large particles settle directly when entering the facility. Therefore, sediment close to the inlet consists mostly of sand and gravel, while the sediment at the outlet is composed of finegrained particles, like clay and silt [4]. The aquatic sediments detain the majority of potentially harmful impurities: heavy metals and organic compounds which enter the surface water with industrial and municipal sewage, and also rainwater. The pollutants are accumulated in the stormwater sediment, resulting in concentrations which are higher than in natural sediments. Contaminants, transported in liquid and solid phase, undergo various processes, which are shown in Fig. 1. In fact, the sediments accumulate persistent organic pollutants (POPs), such as polycyclic aromatic hydrocarbons (PAHs), organochlorine pesticides and polychlorinated biphenyls (PCBs). Consequently, contaminated sediments may pose risk to living organisms and jeopardize the environmental quality of surface waters. Part of the harmful ingredients contained in the sediment can be released into water again as a result of chemical and biochemical processes occurring in the sediment, and also due to mechanical movement of natural processes [5]. Determination of the quality of sediment from the stormwater drainage system and of its effects on the natural environment is most frequently performed assuming the criteria for the evaluation of the degree of sediment contamination.

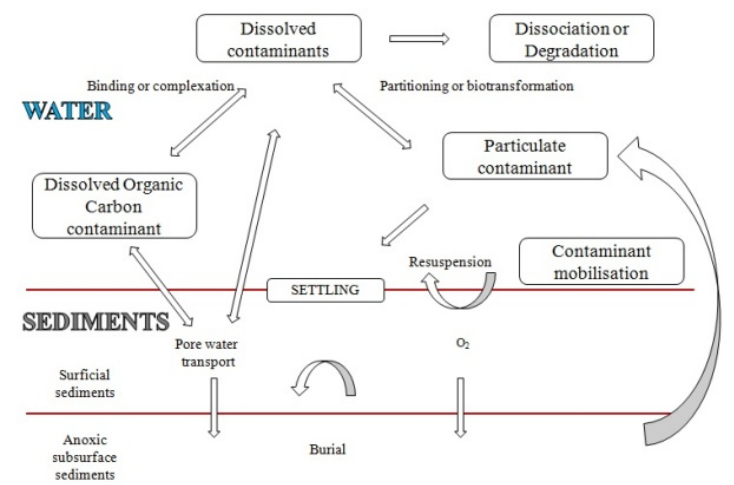

Fig. 1. Migration of contaminants in sediments (modified from Eggleton, 2004) [6].

Currently, Polish legislation does not require that stormwater sediments should be tested for chemical

* Corresponding author: asalata@tu.kielce.pl 
contaminants prior to their removal from sedimentation tanks. Therefore, the results of investigations are referred to the guidelines laid down in the Regulation of the Minister of Environment on soil and ground quality standards [7]. Additionally, in sediment quality assessment, geochemical standards are applied, which is carried out under the State Environmental Monitoring for bottom sediments of lakes and rivers [8, 9]. Considering the significant impact of hazardous substances accumulated in sediments on the natural environment, results of the analysis are, to an increasingly larger extent, referred to the ecotoxicological parameters. The range of sediment contaminant concentrations that are not likely to be associated with biological effects on aquatic organisms was defined using two benchmarks. The Threshold Effects Level (TEL) is the upper limit of the range of sediment contaminant concentrations which predominately produce no effect data entries (i.e., the minimal effects range). Within this range, concentrations of sediment-associated contaminants are not considered to represent significant hazards to aquatic organisms. The Probable Effects Level (PEL) defines the lower limit of the range of contaminant concentrations that are usually, or always associated with adverse biological effects (i.e., the lower limit of the Probable Effects Range). Within the Probable Effects Range, concentrations of sediment-associated contaminants are considered to represent significant and immediate hazards to aquatic organisms [10]. The main objectives of this study were to analyze sediments from three sedimentation tanks of stormwater drainage system located in urban area for hazardous pollutants such as PAHs and heavy metals. Levels of contamination in sediments were then compared with the established standards for ground and soil set in the Regulation of the Minister of Environment, geochemical standards and the ecological screening benchmark - PEL.

\section{Materials and methods}

\subsection{Study site}

Table 1. Catchments selected for investigations

\begin{tabular}{|l|c|c|c|}
\hline & \multicolumn{3}{|c|}{ Catchments } \\
\hline & $\mathrm{P}_{\mathrm{IE}}$ & $\mathrm{W}_{\mathrm{IT}}$ & $\mathrm{J}_{\mathrm{ES}}$ \\
\hline Construction year & 1992 & 2003 & 2001 \\
\hline Tank type & open & open & closed \\
\hline Total catchment area (ha) & 804.6 & 132.0 & 383.9 \\
\hline Residential area (\%) & 63 & 89 & 33 \\
\hline Industrial area (\%) & 9 & 0 & 65 \\
\hline $\begin{array}{l}\text { Meadows, agricultural area } \\
\text { (\%) }\end{array}$ & 27 & 0 & 0 \\
\hline Forests (\%) & 1 & 0 & 1 \\
\hline Green belts (\%) & 0 & 11 & 1 \\
\hline
\end{tabular}

Abbreviations: $\mathrm{P}_{\mathrm{IE}}-$ open tank located near Piekoszowska street, $\mathrm{W}_{\mathrm{IT}}-$ open tank located near Witosa street, $\mathrm{J}_{\mathrm{ES}}$ - closed tank located near Jesionowa street

The sampling stations including of three sedimentation tanks located in the urban area of Kielce city were studied. The facilities have different construction, operating time and land use. The largest and the oldest is the Piekoszowska catchment $\mathrm{P}_{\mathrm{IE}}$ (open tank) representing a wide range of land uses including both low - and high - density residential areas, industrial areas and agricultural, partly forested ones. The two other catchments are classified as typically industrial - the Jesionowa facility $\mathrm{J}_{\mathrm{ES}}$ (closed tank), and typically residential - the Witosa facility $\mathrm{W}_{\mathrm{IT}}$ (open tank) (Table $1)$.

\subsection{Sampling}

The sediment samples were collected in December 2012, described as a winter season, in accordance with the PNEN ISO 5667-15:2009 standard method [11]. Within each sedimentation tank, sediments were collected from two sites in the open reservoirs, namely inlets and outlets, and from the entire bottom of the settling chamber for the closed tank. Sediment samples were collected using a stainless steel standard bottom grab sampler, or Eijkelkamp equipment for sites with difficult access, and placed in acid-washed plastic containers $(\sim$ 1L). Between the series of sample collecting, all equipment was rinsed with water from the reservoir. Then the samples were transported to the laboratory and divided into two parts. The first part was analyzed for particle size distribution and the other was homogenized using a solvent-cleansed stainless steel bucket and spoon. The physical and chemical parameters were measured immediately afterwards.

\subsection{Analytical techniques}

The $\mathrm{pH}$, conductivity and temperature were measured promptly after samples homogenization in accordance with the PN-EN 12176:2004 method using SevenMulti ${ }^{\mathrm{TM}}$ meter (Mettler Toledo) [12]. Organic content, measured as a loss of ignition (LOI), was determined in accordance with the PN-78/C-04541 method [13], which involved drying the sediment at $105^{\circ} \mathrm{C}$ to a constant weight, and then heating it at $550^{\circ} \mathrm{C}$ for $2 \mathrm{~h}$. Sediment particle size distribution was examined using a combination of sieving (wet sieving with different mesh size sieves, Conbest equipment) and laser diffraction (DL) analysis (Mastersizer 3000, Malvern). Sediment samples from stormwater were dried to constant weight in an electric dryer at $105^{\circ} \mathrm{C}$ and passed through a sieve with $2 \mathrm{~mm}$ mesh prior to heavy metal analysis. Sediment samples of $0.2 \mathrm{~g}$ were mineralized in $7 \mathrm{ml}$ nitric acid using microwave oven (Multiwave 3000, Anton Paar). Concentrations of heavy metals: cadmium $(\mathrm{Cd})$, copper $(\mathrm{Cu})$, chromium $(\mathrm{Cr})$, nickel $(\mathrm{Ni})$, lead $(\mathrm{Pb})$ and zinc $(\mathrm{Zn})$ were determined by atomic emission spectrometry with inductively coupled plasma ICP Optima 8000 (Perkin Elmer) with certified multi element standards. Sediment samples with a mass of $1 \mathrm{~g}$ were extracted in dichloromethane to determine the total sum of PAHs. These compounds are grouped in two categories based on their molecular weights and these are low and high. The most commonly studied include as 
follows: Low Molecular Weight PAHs (LMW) containing two- and three-rings with molecular weight from $152 \mathrm{~g} \cdot \mathrm{mol}^{-1}$ to $202 \mathrm{~g} \cdot \mathrm{mol}^{-1}$ include: naphthalene (NAPT), acenaphthylene (ACNY), acenaphthene (ACEN), fluorene (FLUR), phenanthrene (PHEN) and anthracene (ANTH). The High Molecular Weight (HMW) PAHs have four-rings to seven-rings with molecular mass ranging from $228 \mathrm{~g} \cdot \mathrm{mol}^{-1}$ to $278 \mathrm{~g} \cdot \mathrm{mol}^{-1}$ include: fluoranthene (FLTH), pyrene (PYR), benzo[a]anthracene (B(a)A), chrysene (CHRY), benzo[b]fluoranthene $(\mathrm{B}(\mathrm{b}) \mathrm{F})$, benzo[k]fluoranthene $(\mathrm{B}(\mathrm{k}) \mathrm{F})$, benzo[a]pyrene $(\mathrm{B}(\mathrm{a}) \mathrm{P})$, dibenzo[a,h]anthracene $(\mathrm{D}(\mathrm{ah}) \mathrm{A}), \quad$ benzo[g,h,i]perylene $\quad(\mathrm{B}(\mathrm{ghi}) \mathrm{P}), \quad$ and indeno[1,2,3-c,d] pyrene (INPY). Concentrations of PAHs were identified in samples in accordance with the PN-EN 15527:2008 method [14]. To determine the reliability of the PAH data, including the efficiency of extraction methods and interferences that may be introduced during sample preparation, deuterated internal standards were used (d-8 NAPHT and d-12 B(a)A). These standards ensure that the accuracy of the results obtained is independent of the recovery degree. The next step included wetting the sediment sample with acetone, adding acetone with deuterated standards, intensive stirring of the sample and undisturbed evaporation of the acetone. This procedure makes it possible to achieve a similar binding form between standards added and the sediment matter [15]. All PAH concentrations were reported on a dry weight basis.

\subsection{Ecological risk assessment}

To perform ecological risk assessment of sediment contamination, the content of heavy metals $(\mathrm{Cd}, \mathrm{Cu}, \mathrm{Cr}$, $\mathrm{Ni}, \mathrm{Pb}$ and $\mathrm{Zn}$ ) and of polycyclic aromatic hydrocarbons (PAHs) were determined. The results of sediment contaminants were referred to the geochemical criteria defining the purity class of aquatic sediment for heavy metals, as well as the limit values presented in the Regulation of the Minister of Environment [7], and also ecotoxicological indicators - TEL and PEL for heavy metals and PAHs.

\section{Results and discussion}

The measured mean $\mathrm{pH}$, conductivity values and loss of ignition (LOI) together with moisture content in the sediment samples are shown in Table 2. For the treatment facilities of concern, the $\mathrm{pH}$ values constantly fluctuated around mean 7.5. The catchment $\mathrm{P}_{\mathrm{IE}}$ demonstrated the largest conductivity values which may be connected with use of de-icing salt in this area (motorways, streets, pavements at residential part). Sediments from $\mathrm{P}_{\mathrm{IE}}$ site had loose consistency with visible elements of plant and animal residues. They were characterized by high hydration reaching $\sim 65 \%$, while the sediments from the tanks JES and $\mathrm{W}_{\text {IT }}$ had compact form and their hydration ranged from $40 \%$ to $58 \%$. The organic content in the sediment, measured as loss on ignition (LOI), varied from 8 to $11 \%$.
Table 2. The $\mathrm{pH}$ values, conductivity, moisture content and loss of ignition (LOI) in stormwater sediments in the sedimentation tanks

\begin{tabular}{|l|c|c|c|}
\hline & \multicolumn{3}{|c|}{ Sedimentation tanks } \\
\hline & $\mathrm{P}_{\mathrm{IE}}$ & $\mathrm{W}_{\mathrm{IT}}$ & $\mathrm{J}_{\mathrm{ES}}$ \\
\hline $\mathrm{pH}$ & 7.59 & 7.40 & 7.64 \\
\hline Conductivity $\left(\mu \mathrm{S} \cdot \mathrm{cm}^{-1}\right)$ & 364 & 252 & 221 \\
\hline Moisture $(\%)$ & 64.88 & 58.65 & 40.94 \\
\hline LOI $(\%)$ & 9.98 & 11.01 & 8.11 \\
\hline
\end{tabular}

The distribution of sediment particle sizes varied widely in the stormwater settlers surveyed. These differences are most likely due to the facility location and land use. For the catchment area $\mathrm{P}_{\mathrm{IE}}(804.6 \mathrm{ha})$, onethird (27\%) of which is agricultural land, meadows and wastelands. The finest fraction with particle diameters $63 \mu \mathrm{m}$ constituted $68 \%$. The remaining fraction consisted of sands and plant residues. This result of advantage of finest fraction can also be related to a high traffic load in the vicinity of this facility. Areas that are more heavily loaded with traffic show a higher content of fine particles in the sediments compared with those having low traffic loads. That indicates the traffic activity in the catchment area has an impact on the sediment particle size in the treatment facility. Particle abrasive characteristics, associated with high traffic densities, lead to the wash-off of finer particles [16]. The catchment $\mathrm{W}_{\text {IT }}$ is a typical urbanized area were the major fraction of sediment (93\%) was represented by sands, while the dust content was only $7 \%$. Sediments collected from the tank $\mathrm{J}_{\mathrm{ES}}$, which is located in the industrial catchment area, have the most diverse particle size distribution. The fraction with finest particles constituted $16 \%$, the sand fraction formed $79 \%$, and the gravel fraction $5 \%$. It has been reported that sand and gravel particles occur more commonly in the tank inlet, whereas the sediment collected at the outlet consists mainly of the finest fractions [4,16-17].

\subsection{Heavy metals}

The highest values of concentration were observed for zinc in the sediment for tank $\mathrm{W}_{\mathrm{IT}}$, where the values ranged from $267.12 \mathrm{mg} \cdot \mathrm{kg}^{-1}$ to $369.360 \mathrm{mg} \cdot \mathrm{kg}^{-1}$, and for tank $\mathrm{J}_{\mathrm{ES}}$, in which the values varied from $101.06 \mathrm{mg} \cdot \mathrm{kg}^{-1}$ to $358.84 \mathrm{mg} \cdot \mathrm{kg}^{-1}$. The lowest concentrations were observed for cadmium for each tank. The results were referred to the geochemical background, which is a value representing natural conditions and does not include anthropogenic activity. Values exceeding that background are assessed in three level scale (class I weakly contaminated sediments, class II - moderately contaminated sediments and class III - contaminated sediments). Sediment samples are evaluated as contaminated, even if the value exceeding the limit is found for only one sample. The same principle also applies to other criteria. The geochemical classification for selected heavy metals is shown in Table 3.

The results suggest that the concentrations of the studied elements indicate a weak contamination - class I. Values exceeding the geochemical background were thus recorded for all elements except $\mathrm{Cd}$. 
Table 3. Geochemical assessment of stormwater sediments for selected heavy metals and tanks

\begin{tabular}{|c|c|c|c|}
\hline \multirow{2}{*}{ Element } & \multicolumn{3}{|c|}{ Sedimentation tanks } \\
\cline { 2 - 4 } & $\mathrm{P}$ & $\mathrm{W}_{\mathrm{IT}}$ & $\mathrm{J}_{\mathrm{ES}}$ \\
\hline $\mathrm{Cd}$ & $\begin{array}{c}\text { geochemical } \\
\text { background }\end{array}$ & class I & $\begin{array}{c}\text { geochemical } \\
\text { background }\end{array}$ \\
\hline $\mathrm{Cu}$ & class I & class I & class I \\
\hline $\mathrm{Cr}$ & class I & class I & class I \\
\hline $\mathrm{Ni}$ & class I & class I & class I \\
\hline $\mathrm{Pb}$ & class I & class I & class I \\
\hline $\mathrm{Zn}$ & class I & class II & class I \\
\hline
\end{tabular}

Comparing the results of tests on metal concentrations in the analysed sediments with the quality standards for soil and land stipulated in the Regulation of the Minister of Environment [7], it can be stated that concentrations of all examined heavy metals are much lower than the permissible values for urbanised areas. In accordance with the regulation, the concentrations range as follows, for zinc: $300-720 \mathrm{mg} \cdot \mathrm{kg}^{-1}$, cadmium: $4-10$ $\mathrm{mg} \cdot \mathrm{kg}^{-1}$, lead: $100-200 \mathrm{mg} \cdot \mathrm{kg}^{-1}$, copper: $100-200$ $\mathrm{mg} \cdot \mathrm{kg}^{-1}$, nickel: $50-210 \mathrm{mg} \cdot \mathrm{kg}^{-1}$ and chromium: $150-$ $380 \mathrm{mg} \cdot \mathrm{kg}^{-1}$. The ecological risk assessment was therefore based on the ecological screening value - PEL. Heavy metal concentrations according to Probable Effect Level are shown in Table 4.

Table 4. Heavy metal concentrations according to Probable Effect Level (PEL) in the sedimentation tanks

\begin{tabular}{|c|c|c|c|c|}
\hline & \multicolumn{4}{|c|}{ Sedimentation tanks } \\
\hline Element & P IE $_{\text {IE }}$ & $\mathrm{W}_{\text {IT }}$ & J $_{\mathrm{ES}}$ & PEL \\
\hline \multicolumn{5}{|c|}{$\mathrm{mg} \cdot \mathrm{kg}^{-1} \mathrm{dw}$} \\
\hline $\mathrm{Cd}$ & nd & 1.73 & nd & 4.21 \\
\hline $\mathrm{Cu}$ & 81.56 & 78.33 & 74.66 & 108 \\
\hline $\mathrm{Cr}$ & 66.46 & 71.68 & 59.89 & 160 \\
\hline $\mathrm{Ni}$ & 27.51 & 26.37 & 18.55 & 42.8 \\
\hline $\mathrm{Pb}$ & $\mathbf{1 6 8 . 2 2}$ & $\mathbf{1 2 6 . 5 8}$ & $\mathbf{1 1 7 . 6 2}$ & 112 \\
\hline $\mathrm{Zn}$ & 166.75 & $\mathbf{3 2 0 . 0 2}$ & 191.37 & 271 \\
\hline
\end{tabular}

Sediment collected from three different reservoirs may pose a risk to the environment and may have a negative impact on living organisms. All sedimentation tanks have high concentration of lead, but only one ( $\mathrm{W}_{\text {IT }}$ sedimentation tank) has high value of zinc. The principal source of lead deposition in stormwater sediments was the combustion of leaded gasoline prior to conversion to unleaded gasoline. However, the concentrations of lead in gasoline due to natural sources in the crude oil still often cause stormwater runoff from highways and streets to have excessive concentrations of lead compared with aquatic system standards. Zinc is an additive in the manufacture of the rubber used in tires, and cadmium is a trace impurity occurring with zinc, which is observed in the $\mathrm{W}_{\text {IT }}$ samples. However, corrosion of galvanized steel (used in culverts and roofs) can be a major source of emission of zinc from aqueous to solid phase.

\subsection{Polycyclic aromatic hydrocarbons}

Median $\sum$ PAHs concentration values ranged widely in sediment samples from $27.433 \mathrm{mg} \cdot \mathrm{kg}^{-1}$ in the Witosa sedimentation tank to $48.179 \mathrm{mg} \cdot \mathrm{kg}^{-1}$ in the Piekoszowska sedimentation tank (Fig. 2).

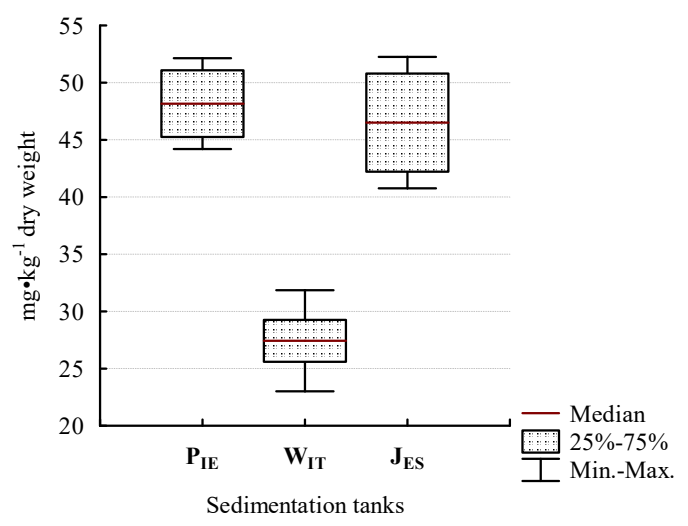

Fig. 2. Total PAHs sediment concentrations (with the median) in the sedimentation tanks $\left(\mathrm{mg} \cdot \mathrm{kg}^{-1}\right.$ dry weight)

PAHs were also detected in the sediments of the Jesionowa settler and had also high median value of $46.511 \mathrm{mg} \cdot \mathrm{kg}^{-1}$. Thus, the results for a typical industrial facility are similar to the results for an area with mixed land use. Similar trends were apparent with both the $\sum \mathrm{PAH}_{\mathrm{LMW}}$ and $\sum \mathrm{PAH}_{\mathrm{HMW}}$ (Fig. 3).

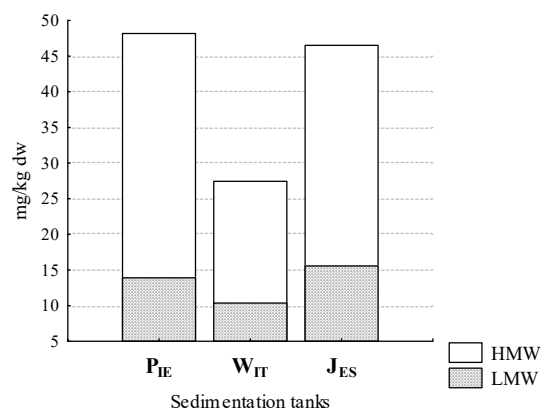

Fig.3. Levels of mean $\sum$ PAH Lмw and $\sum$ PAHнмw in the sedimentation tanks ( $\mathrm{mg} \cdot \mathrm{kg}^{-1}$ dry weight)

Levels of mean $\sum \mathrm{PAH}_{\mathrm{LMW}}$ were significantly higher in sediments from the industrial catchment $\mathrm{J}_{\mathrm{ES}}(15.57$ $\mathrm{mg} \cdot \mathrm{kg}^{-1}$ ) and from the largest catchment area PIE with mixed land use $\left(13.90 \mathrm{mg} \cdot \mathrm{kg}^{-1}\right)$ than in those from the residential catchment $\mathrm{W}_{\mathrm{IT}}\left(10.36 \mathrm{mg} \cdot \mathrm{kg}^{-1}\right)$. Levels of $\sum \mathrm{PAH}_{\mathrm{HMW}}$ in industrial and mixed land use site ponds (30.940 $\mathrm{mg} \cdot \mathrm{kg}^{-1}$ and $34.274 \mathrm{mg} \cdot \mathrm{kg}^{-1}$ ) were substantially higher compared with the residential site $\left(17.063 \mathrm{mg} \cdot \mathrm{kg}^{-}\right.$ $\left.{ }^{1}\right)$, accordingly. As regards the concentration of particular compounds of PAHs, the PEL benchmark high exceedances were observed (Fig. 4 and Table 5).

Generally, the sediments from each of the three sedimentation tanks selected for the analysis exceeded the PEL values for each compound of PAHs group except for dibenzo(a,h)anthracene. The highest concentration was observed for fluoranthene (FLTH), which ranged from $7.996 \mathrm{mg} \cdot \mathrm{kg}^{-1}$ in $\mathrm{W}_{\mathrm{IT}}$ samples to $15.793 \mathrm{mg} \cdot \mathrm{kg}^{-1}$ in $\mathrm{P}_{\mathrm{IE}}$. Contrastingly, the lowest values were observed for $\mathrm{D}(\mathrm{ah}) \mathrm{A}$. PEL hazard quotients indicated high PAH contamination in the sediment samples from both study sites. HQ-PEL points to 
multiple exceedances from 1.12 for NAPT in JES to 18.68 for ACNY in $\mathrm{P}_{\mathrm{IE}}$. For the individual PAH analytes, several results were similar to those described for the mean $\sum$ PAH16 levels.

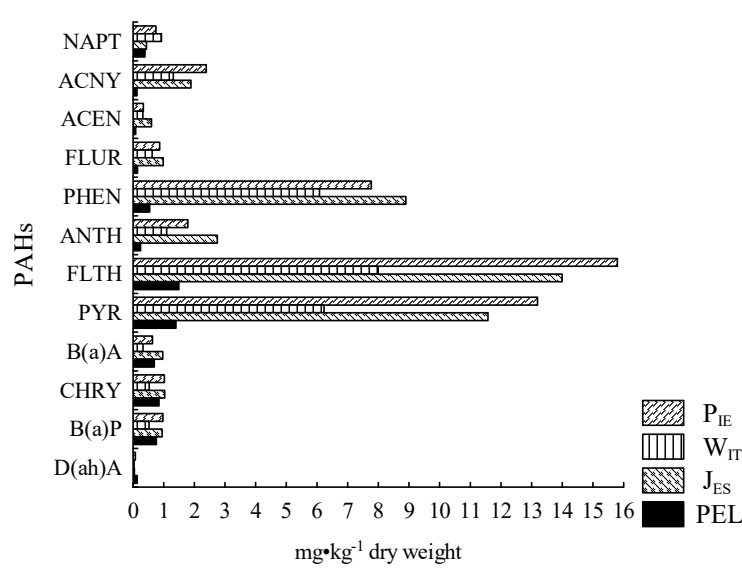

Fig.4. Levels of mean for individual $\mathrm{PAH}_{\mathrm{s}}$ concentration in the sedimentation tanks ( $\mathrm{mg} \cdot \mathrm{kg}^{-1}$ dry weight)

Table 5. Hazard quotients for PEL (HQ-PEL). The bold values indicate the hazard quotient greater than 1.0

\begin{tabular}{|c|c|c|c|}
\hline PAH & PIE & W $_{\text {IT }}$ & J $_{\text {ES }}$ \\
\hline \multicolumn{4}{|c|}{$\mathrm{mg} \cdot \mathrm{kg}^{-1}$} \\
\hline NAPT & $\mathbf{1 . 9 1}$ & $\mathbf{2 . 3 7}$ & $\mathbf{1 . 1 2}$ \\
\hline ACNY & $\mathbf{1 8 . 6 8}$ & $\mathbf{1 0 . 2 7}$ & $\mathbf{1 4 . 7 6}$ \\
\hline ACEN & $\mathbf{3 . 8 4}$ & $\mathbf{3 . 6 8}$ & $\mathbf{6 . 8 8}$ \\
\hline FLUR & $\mathbf{6 . 0 3}$ & $\mathbf{4 . 3 4}$ & $\mathbf{6 . 8 5}$ \\
\hline PHEN & $\mathbf{1 4 . 2 9}$ & $\mathbf{1 1 . 1 8}$ & $\mathbf{1 6 . 3 5}$ \\
\hline ANTH & $\mathbf{7 . 2 9}$ & $\mathbf{4 . 4 7}$ & $\mathbf{1 1 . 2 3}$ \\
\hline FLTH & $\mathbf{1 0 . 5 7}$ & $\mathbf{5 . 3 5}$ & $\mathbf{9 . 3 7}$ \\
\hline PYR & $\mathbf{9 . 4 3}$ & $\mathbf{4 . 4 5}$ & $\mathbf{8 . 2 8}$ \\
\hline B(a)A & 0.91 & 0.47 & $\mathbf{1 . 4 0}$ \\
\hline CHRY & $\mathbf{1 . 2 1}$ & 0.63 & $\mathbf{1 . 2 2}$ \\
\hline B(a)P & $\mathbf{1 . 2 8}$ & 0.69 & $\mathbf{1 . 2 4}$ \\
\hline D(ah)A & 0.56 & 0.24 & 0.35 \\
\hline P PAHs & $\mathbf{2 . 7 2}$ & $\mathbf{1 . 5 5}$ & $\mathbf{2 . 6 3}$ \\
\hline LMW & $\mathbf{9 . 6 6}$ & $\mathbf{7 . 2 0}$ & $\mathbf{1 0 . 8 1}$ \\
\hline HMW & $\mathbf{4 . 7 5}$ & $\mathbf{2 . 3 4}$ & $\mathbf{4 . 2 8}$ \\
\hline
\end{tabular}

For the sedimentation tanks of concern, PEL-HQ values ranged from 1.12 to 2.37 for NAPT, from 10.27 to 18.68 for ACNY, from 3.68 to 6.88 for ACEN, from 4.34 to 6.85 for FLUR, from 11.18 to 16.35 for PHEN, from 4.47 to 11.2 for ANTH, from 5.35 to 10.57 for FLTH, from 4.45 to 9.43 for PYR, from 0.47 to 1.40 for $\mathrm{B}(\mathrm{a}) \mathrm{A}$, from 0.63 to 1.22 for CHRY and from 0.69 to 1.28 for $\mathrm{B}(\mathrm{a}) \mathrm{P}$. The most values exceeding the HQ-PEL equal 1.0 were observed in the JES tank (fourteen out of fifteen available). One exceedance less was noticed for the PIE. The results indicate that the LMW fraction provided the largest contribution of PAH pollution.

Additionally, five $\mathrm{PAH}$ isomer ratios with equal molecular mass but different thermodynamic stability (FLTH/PYR, PHEN/ANTH, FLTH/LFLTH:PYR and ANTH/ $\sum$ ANTH:PHEN) and the ratio of LMW to HMW
(LMW/HMW) were calculated for the sediment samples to determine probable PAH sources (Table 6).

Table 6. Isomer ratios of PAH concentrations

\begin{tabular}{|c|c|c|c|c|c|}
\hline \multirow{2}{*}{ Isomer ratio } & \multirow{2}{*}{$\begin{array}{c}\text { Pyrogenic } \\
\text { source }\end{array}$} & \multirow{2}{*}{$\begin{array}{c}\text { Petrogenic } \\
\text { source }\end{array}$} & \multicolumn{3}{|c|}{$\begin{array}{c}\text { Sedimentation } \\
\text { tanks }\end{array}$} \\
\hline & & & $P_{\text {IE }}$ & $\begin{array}{c}\mathbf{W}_{\mathrm{I}} \\
T\end{array}$ & $\mathbf{J}_{\mathbf{E S}}$ \\
\hline LMW/HMW & $<1.0$ & $>1.0$ & $\begin{array}{c}0.4 \\
4\end{array}$ & $\begin{array}{c}0.6 \\
6\end{array}$ & $\begin{array}{c}0.5 \\
4\end{array}$ \\
\hline PHEN/ANTH & $<10$ & $>10$ & $\begin{array}{c}4.3 \\
5\end{array}$ & $\begin{array}{c}5.5 \\
5\end{array}$ & $\begin{array}{c}3.2 \\
3\end{array}$ \\
\hline FLTH/PYR & $>1.0$ & $<1.0$ & $\begin{array}{c}1.2 \\
0\end{array}$ & $\begin{array}{c}1.2 \\
8\end{array}$ & $\begin{array}{c}1.2 \\
1\end{array}$ \\
\hline $\begin{array}{l}\text { FLTH/ऽFLT } \\
\text { H:PYR }\end{array}$ & $>0.5$ & $<0.5$ & $\begin{array}{c}0.5 \\
4\end{array}$ & $\begin{array}{c}0.5 \\
6\end{array}$ & $\begin{array}{c}0.5 \\
5\end{array}$ \\
\hline $\begin{array}{l}\text { ANTH/ } \sum \text { AN } \\
\text { TH:PHEN }\end{array}$ & $>0.1$ & $<0.1$ & $\begin{array}{c}0.1 \\
9\end{array}$ & $\begin{array}{c}0.1 \\
5\end{array}$ & $\begin{array}{c}0.2 \\
4\end{array}$ \\
\hline
\end{tabular}

Generally, pyrogenic or combustion sources of PAHs are indicated by high ratios, namely: FLTH/PYR $>1$; FLTH/ $/$ FLTH:PYR $>0.5$ and ANTH/ $/$ ANTH:PHEN $>0.1$ and low ratios of: PHEN/ANTH $<10$ and LMW/HMW $<1$. By contrast, petrogenic and other non-combustion sources of PAH are indicated by low FLTH/PYR ratios $(<1)$ and high PHEN/ANTH and LMW/HMW ratios $(>10$ and $>1$, respectively). A single ratio can often be misleading, so multiple ratios are often used. These ratios were calculated using the average concentrations of individual PAH compounds sampled from each sedimentation tank. All calculated ratios indicate a pyrogenic source, so PAHs are formed and emitted primarily during incomplete combustion processes of organic matter from different sources such as internal combustion engines, home heating, power generation from fossil fuels, industrial activities and biomass burning $[18,19]$.

\section{Conclusions}

The results of the current study on sediments from stormwater drainage system indicate significant differences in determining the degree of risk to the environment due to the high tendency to accumulate chemical contaminants. The differences primarily arise from difficulties in the interpretation of contemporary legal regulations and standards for sediments.

Sediments from the sedimentation tanks $\mathrm{P}_{\mathrm{IE}}, \mathrm{W}_{\mathrm{IT}}$ and $\mathrm{J}_{\mathrm{ES}}$ were slightly alkaline, characterized by high hydration and a variety of particle size distribution which closely corresponds to the location and land use of the catchments selected for investigations.

Chemical analyses of sediments confirmed the presence of heavy metals such as copper, chromium, nickel, lead and zinc as well as polycyclic aromatic hydrocarbons at each of the study sites.

The results were referred to the standards specified in the Regulation of the Minister of Environment. The measured values were found to be within the ranges stated by the standards. With respect to geochemical criteria and the ecotoxicological benchmark PEL, the sediments exhibit an excessive content of heavy metals 
and polycyclic aromatic hydrocarbons and may adversely affect aquatic organisms.

PAH isomer ratios with equal molecular mass but different thermodynamic stability calculated for the sediment samples showed that the probable PAH sources is pyrogenic.

\section{Acknowledgement}

Publication supported by the Polish Ministry of Science and Higher Education as a part of the program of activities disseminating science from the project ,Organization of the First International Science Conference - Ecological and Environmental Engineering”, 26-29 June 2018, Kraków.

The work reported herein was undertaken as part of the project 2990/B/P01/2011/40 funded by the National Science Center, Poland.

\section{References}

1. J. Królikowska, A. Królikowski. Rainwater. Disposal, management, pre-treatment and use (in Polish). Publisher Seidel - Przywecki (2012)

2. T. Hvitved - Jacobsen, Y.A. Yousef. Studies in Environmental Science 44:165-208 (1991)

3. Discharge consent for rainwater and thaw-water treated at the Jarzabek treatment facility (in Polish), Kielce (2007)

4. K. Karlsson, M.Viklander, L. Scholes, M. Revitt, J Hazard. Mater. 178: 612-618 (2010)

5. The Condition of the Natural Environment in the Świętokrzyskie Province in the years 2009-2010 (in Polish). A report compiled under the supervision of Małgorzata Janiszewska at the Regional Inspectorate for Environmental Protection in Kielce. Library of Environmental Monitoring, Kielce (2011)

6. J. Eggleton, K.V. Thomas, Environmental International 30:973-980 (2004)

7. Regulation of the Minister of Environment of 9 Sept. 2002 on soil and land quality standards (J. of Laws No. 165, item 1359)
8. I. Bojakowska, T. Gliwicz, K. Małecka Results of geochemical tests on Poland's aquatic sediments in the years 2003-2005 (in Polish). Environmental Protection Inspection. Warszawa (2006)

9. I. Bojakowska, G. Sokołowska Geochemical classes of aquatic sediment purity (in Polish). Geological Review 46 (1):49-54 (1998)

10. D.D. MacDonald Approach to the assessment of sediment quality in Florida Coastal Waters. Volume 1 - Development and evaluation of sediment quality assessment guidelines. Florida Department of Environmental Protection Office of Water Policy (2000)

11. PN-EN ISO 5667-15:2009. Water quality. Sampling. Part 15: Guidance on the preservation and handling of sludge and sediment samples.

12. PN-EN 12176:2004. Characterisation of Sludge. Determination of $\mathrm{pH}$ value.

13. PN-78/C-04541. Water and Wastewater. Determination of Dry Residue, Residue on Ignition, Loss on Ignition and Dissolved Substances, Dissolved Mineral Substances and Dissolved Volatile Substances.

14. PN-EN 15527:2008. Characterisation of Waste. Determination of Polycyclic Aromatic Hydrocarbons (PAH) in Waste Using Gas Chromatography Mass Spectrometry (GC/MS).

15. L. Wolska, M. Gdaniec-Pietryka, P. Konieczka, J. Namieśnik Talanta 78:730-735 (2009)

16. J. Marsalek, P.M. Marsalek. Characteristics of sediments from a stormwater management pond. Water Science and Technology, 36, Issue 8:117-122 (1997)

17. A. Królikowski, K. Garbarczyk, J. GwoździejMazur, A. Butarewicz. Sediments formed in stormwater sewer facilities (in Polish). Monograph 35. Lublin (2005)

18. M.B Yunker et al. Organic Geochemistry. 33:489515 (2002)

19. Y. Chen, L. Zhu, R. Zhou J Hazard. Mater. 141:148155 (2007) 